\title{
RELATIONSHIP OF SERUM DIPEPTIDYL PEPTIDASE-IV ACTIVITY AND ANTI-CASEIN ANTIBODIES TO GASTROINTESTINAL SYMPTOMS AMONG CHILDREN WITH AUTISM SPECTRUM DISORDER: AN EGYPTIAN STUDY
}

\author{
INAS R EL-ALAMEEY ${ }^{1 *}$, HANAA H AHMED ${ }^{2}$, IHAB M EID ${ }^{3}$, GHADA EL-DORY ${ }^{3}$, MANAL GAMEEL ${ }^{4}$
}

${ }^{1}$ Child Health Department, National Research Centre, Egypt. ${ }^{2}$ Hormones Department, National Research Centre, Egypt. ${ }^{3}$ Medical Childhood Studies Department, Institute of Postgraduate Childhood Studies, Ain Shams University, Egypt. ${ }^{4}$ Zahira Abdeen Hospital, Ministry of Health, Egypt. Email: inasno@hotmail.com

Received: 18 September 2017, Revised and Accepted: 15 December 2018

\section{ABSTRACT}

Objectives: The objectives of the study were to assess serum dipeptidyl peptidase-IV (DPP-IV) activity in autistic children suffering from severe gastrointestinal (GI) disorder and to examine the hypothesis that there is a link between DPP-IV activity in serum and GI disorder in a subgroup of children with autism spectrum disorder (ASD).

Subjects and Methods: Serum levels of casein antibodies and DPP-IV enzyme activity from 40 autistic children with chronic GI symptoms, and 40 of age-matched children without autism or gastrointestinal (GI) symptoms were assayed using enzyme-linked immunosorbent assay kits.

Results: In comparison with controls, developmental milestones were delayed among autistic children. The serum DPP-IV activity was significantly lower in the studied patients $(\mathrm{p}<0.05)$, while the mean serum levels of casein antibodies were statistically significantly higher in the studied patients $(\mathrm{p}<0.01)$. Multiple logistic regression analysis recorded significant association between the high serum level of antibodies to casein, food selectivity and recurrent attacks of abdominal pain $(\mathrm{p}<0.05)$, while the low serum DPP-IV enzyme activity was associated with recurrent attacks of abdominal pain in the studied patients with a prediction of $95 \%(\mathrm{p}<0.05)$.

Conclusions: Serum levels of casein antibodies were higher in children with ASD, and maybe contributes to their abdominal pain, and food selectivity. Serum DPP-IV enzyme activity was lower and associated with recurrent attacks of abdominal pain in the studied patients. They may benefit from a supplemental digestive enzyme formula.

Keywords: Autism spectrum disorder, Dipeptidyl peptidase-IV, Anti-casein antibodies, Gastrointestinal symptoms.

(C) 2018 The Authors. Published by Innovare Academic Sciences Pvt Ltd. This is an open access article under the CC BY license (http://creativecommons. org/licenses/by/4. 0/) DOI: http://dx.doi.org/10.22159/ajpcr.2018.v11i4.22627

\section{INTRODUCTION}

Autism is a neurodevelopmental disorder characterized by impairments in verbal and non-verbal communication; language and reciprocal social interaction with patterns of restricted and repetitive behaviors [1]. The etiology and pathogenesis of autism remain unexplained and assumed either due to genetic susceptibility or environmental exposure or by both during brain developmental stage of the children. The prevalence of autism spectrum disorder (ASD) has increased by more than 10 times, and it is estimated as 1 in 88 children in the United States [2].

Casein is the protein observed in dairy products and some medication, including the pill or stomach tablets. Proteins in milk create specific casein antibodies in large amounts which initiate immediate or delayed inflammatory reaction [3].The patients can manifested either very quickly after feeding (rapid onset) or up to several days or even weeks after consuming the dairy products (slow onset). The most common symptoms are gastrointestinal (GI), respiratory, and cutaneous eczema [4-6].

Dipeptidyl peptidase-IV (DPP-IV) (CD26), a proteolytic proteindigesting enzyme, has been contained within the cells lining the small intestine villi. This enzyme plays an important role in the digestion of casein containing foods [7]. Deficiency in DPP-IV enzyme may cause maldigestion of these dietary proteins and produce small peptides that bind to opioid receptors in the brain leading to interference with cognitive function and contribute to the appearance of symptoms in autistic children [8-10]. DPP-IV also originates from T-lymphocytes. There is a very significant downregulation in CD26 expression on lymphocytes in some individuals with autism who have an allergic response to casein (milk allergy). The dietary peptides (from casein) may bind to DPP-IV (CD26), leading to the production of autoantibody, modulation and expression of immune as well as inflammatory reactions in autistic children [11].

Till now the exact medications for management of GI symptoms in ASD children are unknown. Optimal keeping of a free diet from casein is difficult because many everyday foods and items are hidden resources. The treatment of autistic children is mainly directed toward the controlling of symptoms. Bashir and AL-Ayadhi [12] supposed that DPPIV supplementation can requite for the slow digestion, of protein and can be beneficial in lowering or eliminating the inflammatory response related to casein, decreasing the need for a highly restricted food regimen. Therefore, this study aimed to measure antibody response to casein protein through assessing serum levels of casein antibody, and DPP-IV enzyme activity among Egyptian autistic children and evaluates their relationship with the GI symptoms, and feeding behavior of these children.

\section{SUBJECTS AND METHODS}

Subjects

Research design and setting

This descriptive case-control study included 80 children being divided into two groups; 40 autistic children ( 30 boys and 10 girls) in Group I, their ages ranged from aged 6 to 12 years with mean of $8.2 \pm 2.4$ years. A control group was selected, which included 40 age and gender- 
matched unrelated apparently healthy children in Group II. This study was carried out in the outpatient Clinic of Center for Care of Children with Special Needs, Institute of Postgraduate Childhood Studies; Ain Shams University, Egypt.

\section{Sample size}

The sample size was calculated to assess of the risk factors probably affecting serum levels of casein antibodies and DPP-IV activity of children with autism.

\section{Diagnosis}

The diagnosis of pervasive developmental disorders was established on the basis of medical history, physical examination according to the fifth revision of the American Psychiatric Association's Diagnostic and Statistical Manual of Mental Disorders $5^{\text {th }}$ Edition (DSM-V) criteria by pediatric psychiatrists [13].The severity was evaluated using the childhood autism rating scale (CARS) for autistic characters [14].

The term "food selectivity" has been used to refer to food refusal, and restricted intake focusing on less vegetables, salads, high protein, high starch or sweet. Food selectivity, or "picky eating," is often observed in young children and is a frequent cause of parental concern. Food selectivity is more commonly reported in children with developmental disabilities, particularly in children with ASDs, compared with typically developing children [15].

\section{Criteria of selection}

The inclusion criteria for selection included all children with autism and GI symptoms, who had been regularly attending outpatient Clinic of Center for Care of Children with Special Needs, Institute of Postgraduate Childhood Studies; Ain Shams University, Egypt. Patients were excluded from the study if they were suffering from progressive neurological disorders or unstable epilepsy.

\section{Ethical approval}

The study was approved by the Research Ethics Committee of Institute of Postgraduate Childhood Studies; Ain Shams University with ethical number 29.6.2010. Written informed consent was obtained from the parents of the participating patients and controls.

\section{Methods}

All children were subjected to full detailed history including age, sex of patients, and history of behavior disorders, the presence of convulsions, duration and course of disease, age of beginning of treatment and the treatment regimen, comorbidity or complications. Inquiring about special diets, a prior of food allergy, types of food selectivity, frequent vomiting, a prior diagnosis of gastroesophageal reflux, abdominal pain, abnormal stool pattern, characteristics of the bowel movements, diarrhea, constipation, use of laxatives or enemas, fecal soiling, number of bowel movements per day, and prior visits to a gastroenterologist.

Developmental history was taken laying stress on all developmental milestones (gross motor, fine motor, sphincter control, language, cognitive development, and social milestones). Furthermore, behavioral disorders (history of pica and stereotypic behavior) and dietary history (being breast or artificially fed, duration, weaning history, and problems during weaning) were noted.

All autistic children were submitted to thorough clinical examination including neurological examination and a full clinical child psychiatric evaluation for diagnosis of autistic spectrum disorder and exclusion of other psychiatric disorders according to DSM-V.

The severity of autistic symptomatology was measured by the CARS. It consists of 15 categories, each rated on a four-point scale. The individual is considered nonautistic when his total score falls in the range of 15-29. Based on the administration of multiple assessments, insights into various aspects of autism are gained.

\section{Biochemical analyses}

From all cases, and controls, 5 cc venous blood samples were obtained by venipuncture and collected in plain tubes, allowed to clot at room temperature, and then centrifuged for $10 \mathrm{~min}$. Serum human casein antibody level was measured using an enzyme-linked immunosorbent assay (ELISA) using kit obtained from Glory Bioscience, USA according to the method described by Greenberg [16]. The concentration of casein antibody level in the samples was determined directly from the standard curve. Cutoff values for serum human casein $<200 \mathrm{ng} / \mathrm{mL}$ is considered to be normal.

Serum DPP-IV enzyme activity was quantified by an ELISA using kit purchased from Glory Bioscience, USA according to manufacturer's instruction. The cutoff value was calculated from healthy control samples.

\section{Statistical analysis}

Statistical analyses were performed using the SPSS statistical package software for Windows version 22 (SPSS Inc., Chicago, Illinois, USA). Data obtained from the research will be organized, tabulated and analyzed through IBM personal computer. Parametric variables are expressed as the mean \pm standard deviation. Differences between parametric variables among the controls and the studied patient's groups were analyzed using two-tailed unpaired t-test. Qualitative variables were assessed by Chi-square test. Multiple logistic regressions were performed to identify for the association between serum DPP-IV activity, casein antibodies and GIT symptoms. $p<0.05$ was considered significant difference and $\mathrm{p}<0.005$ was considered the highly significant difference.

\section{RESULTS}

A total number of 40 autistic patients, $60 \%$ males and $40 \%$ females were recruited into this study, giving a male to female ratio of 1.5:1 and a significant sex distribution $(p<0.05)$. The age of the patients ranged from 6 to 12 years with a mean of $8.32 \pm 0.7$ years

The degree of CARS in autistic patients: $37.5 \%$ of our patients showed mild degree of autism with CARS, $35 \%$ with moderate degree of autism, and $27.5 \%$ with severe autism. Classification of the patients according to CARS is shown in Table 1.

Delayed speech was present in $72 \%$ of our patients, tendency to play lonely in $51 \%$, inattention to mother and loss of eye contact in $32 \%$. Fig. 1 showed the specific presenting symptoms of autism.

In our study, developmental milestones were retarded among autistic children compared to the control group. Table 2 showed a comparison between the studied patients and controls regarding to developmental milestones.

Concerning feeding pattern of the studied patients, food sensitivity to particular foods was present in (47.5\%), anorexia in (50\%), and food selectivity with refusing different kinds of foods in $(40 \%)$. Table 3 showed feeding pattern of the studied patients.

The mean serum DPP-IV activity was statistically significantly lower in the studied patients $(3964 \pm 383.99 \mathrm{IU} / \mathrm{L})$ compared to the controls $(3839.14 \pm 99.08 \mathrm{IU} / \mathrm{L})(\mathrm{p}<0.05)$, while the mean serum levels of casein antibodies were statistically significantly higher in the studied patients

Table 1: Classification of the patients according to CARS

\begin{tabular}{ll}
\hline Groups & Cases n (\%) \\
\hline Mild & $15(37.5)$ \\
Moderate & $14(35)$ \\
Severe & $11(27.5)$ \\
Total & $40(100)$ \\
\hline
\end{tabular}

CARS: Childhood autism rating scale 
Table 2: Comparison between the studied patients and controls as regards developmental milestones

\begin{tabular}{llll}
\hline Items & Cases group $\mathbf{n = 4 0 ( \% )}$ & Control group n=40 (\%) & t \\
\hline Delayed walking & $15(37.5)$ & $1(2.5)$ & 47.9 \\
Delayed sitting & $28(70)$ & $0(0)$ & 28.68 \\
Delayed head support & $40(100)$ & $0(0)$ & 25.2 \\
Afraid & $15(37.5)$ & $4(10)$ & $0.00^{* *}$ \\
No wave bye-bye & $28(70)$ & $2(5)$ & $0.00^{* *}$ \\
No mothers recognition & $36(90)$ & $0(0)$ & $0.00^{* *}$ \\
Delayed speech & $40(100)$ & $0(0)$ & $0.00^{* *}$ \\
\hline
\end{tabular}

**Highly significant difference at $\mathrm{p}<0.01$

Table 3: Feeding pattern of the studied patients group

\begin{tabular}{ll}
\hline Variables & Cases n (\%) \\
\hline Food sensitivity & $19(47.5)$ \\
Food selectivity & $16(40)$ \\
Anorexia & $20(50)$ \\
\hline
\end{tabular}

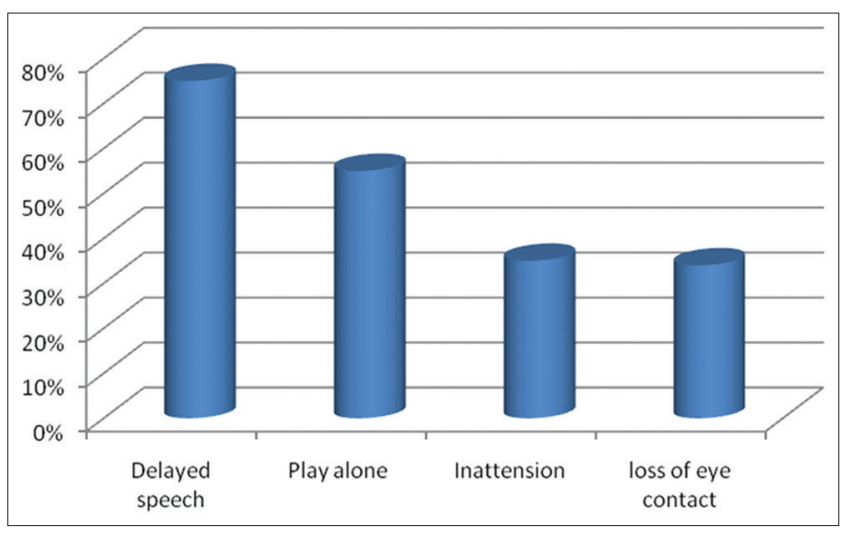

Fig. 1: The specific presenting symptoms of autism

(681.37 $\pm 120.26 \mathrm{IU} / \mathrm{L})$ compared to the controls $(214.52 \pm 21.58 \mathrm{IU} / \mathrm{L})$ $(\mathrm{p}<0.01)$, as shown in Table 4.

There were no significant sex differences in the serum levels of casein antibodies and DPP-IV in the studied patients, as shown in Table 5.

Multiple logistic regression analysis showed significant association between the serum DPP-IV enzyme activity and significant causative factors of recurrent attacks of abdominal pain in the studied patients with a prediction of $95 \%(\mathrm{p}<0.05)$. Table 6 showed multiple logistic regression analysis of factors associated with low serum DPP-IV enzyme activity in the studied patients.

On analyzing risk factors using multiple logistic regression models, food selectivity and recurrent attacks of abdominal pain were statistically associated with high serum casein antibody level in the studied patients with a prediction of $95 \%(\mathrm{p}<0.05)$. Table 7 showed multiple logistic regression analysis of factors associated with high serum casein antibody level in the studied patients.

\section{DISCUSSION}

ASD is a common neurodevelopmental disorder that is manifested by repetitive behaviors, social and communication problems, abnormal movement patterns, and sensory dysfunction $[17,18]$. Autistic children have difficulty in presenting the words in their proper meaning do not like alteration in routines, and act in abnormal behaviors [19].

A total number of 40 autistic patients, $60 \%$ males and $40 \%$ females were recruited into our study, giving a male to female ratio of 1.5:1 and a significant sex distribution $(\mathrm{p}<0.05)$. This finding is in agreement with
Itzchak et al., [20] who reported that autism is more often in boys than girls where 1 in 54 boys and 1 in 252 girls are affected with autism.

In our present study, $72 \%$ of our patients suffered from delayed speech, $51 \%$ started with symptoms like to play alone, $32 \%$ presented with inattention to mother, and loss of eye contact. In all studied patients, developmental milestones were delayed among autistic children compared to the controls. This is in agreement with Noens et al. [21] who mentioned that approximately a third to a half of autistic children with do not develop adequate natural speech to fulfill their daily communication demands. In addition, Volkmar and klin [22] stated that social aberrations as poor eye contact, inability to utilize nonverbal gestures, and lack of ability to play were recognizable in ASDs children. A study by Zhongguo [23] demonstrated that autistic children exhibited a series of atypical behaviors, involving no social smile, no eye contact, no response to own name, and delay in speech.

In the present study, all studied developmental milestones were significantly delayed in our autistic children versus the controls. In agreement to our findings, Filipek et al. [24] noted delayed speech and language skills in children with autism. McPartland and Klin [25] discovered that autistic children may be retarded in acquiring motor skills, or have an abnormal gait. Juneja et al. [26] observed that $96 \%$ of autistic children have motor developmental delay being associated with qualitative impairment in social interaction and verbal communication.

To our best knowledge, there is no available research in the literature regarding the connection between DPP-IV enzyme and casein intolerance among autistic children in Egypt. Therefore, our study is considered to be the first clinical study that measured antibody response to casein and DPP-IV enzyme activity among autistic children in Egypt and examined their relationship with their GI symptoms and feeding pattern.

Casein is found in foods containing milk ingredients. Normally, casein is digested by digestive enzymes, but the enzymes of some cases are not as effective leading to the appearance of the symptoms of intolerance to casein include itching, abdominal pain, nausea, vomiting, or diarrhea $[27,28]$.

Concerning feeding pattern of our studied patients, food sensitivity presented in $47.5 \%$, anorexia in $42.2 \%$, refusing different kinds of foods such as vegetables, salads and fresh fruit and foods selectivity in $40 \%$, and $70.3 \%$ of patients reported GIT signs and symptoms. Such symptoms included chronic diarrhea in $96.7 \%$, vomiting in $43.3 \%$, abdominal pain in $63.3 \%$, and abdominal distension in $23.3 \%$. Our results converge with previous data reported by Valicenti-McDermott et al. [27] who observed that $70 \%$ of children with autism have GIT problems, while Campbell et al. [28] reported 43\% of children with autism had GIT problems in the form of diarrhea, abdominal pain, bloating, or vomiting.

In our present study, the mean serum levels of casein antibodies were statistically significantly higher in the studied patients relative to the controls $(\mathrm{p}<0.01)$. This finding is in respect with Jyonouchi et al. [3], who proved a link between casein intolerance and autism. They explained this link as children who have casein intolerance are not able to fully metabolize food containing casein proteins. This leads to the 
Table 4: Comparison of serum DPP-IV enzyme activity and casein antibodies levels of the studied patients and control groups

\begin{tabular}{|c|c|c|c|c|}
\hline Variables & Cases $(n=40)$ & Control $(n=40)$ & $\mathbf{t}$ & $\mathbf{p}$ \\
\hline \multicolumn{5}{|c|}{ Serum DPP-IV enzyme activity } \\
\hline Mean \pm SD & $3964 \pm 383.99$ & $3839.14 \pm 99.08$ & 2.05 & $<0.05$ \\
\hline Range & $2950-4800$ & $3700-4050$ & & \\
\hline \multicolumn{5}{|c|}{ Serum casein antibodies } \\
\hline Mean \pm SD & $681.37 \pm 120.26$ & $214.52 \pm 21.58$ & 25.15 & $<0.01$ \\
\hline Range & $425-882$ & $200-273$ & & \\
\hline
\end{tabular}

Table 5: Comparison of serum DPP-IV enzyme activity and casein antibodies levels of the studied patients as regard gender

\begin{tabular}{|c|c|c|c|c|}
\hline Variables & Males $(n=40)$ & Females $(n=40)$ & $t$ & p \\
\hline $\begin{array}{l}\text { Serum DPP-IV enzyme activity } \\
\text { Mean } \pm \text { SD }\end{array}$ & $3912 \pm 291$ & $3825.14 \pm 231$ & 0.911 & 0.346 \\
\hline $\begin{array}{l}\text { Serum casein antibodies } \\
\text { Mean } \pm \text { SD }\end{array}$ & $440 \pm 242$ & $500 \pm 314$ & 0.702 & 0.484 \\
\hline
\end{tabular}

*Significant difference at $\mathrm{p}<0.05$. DPP-IV: Dipeptidyl peptidase-IV, SD: Standard deviation

Table 6: Multiple logistic regression analysis of factors associated with low serum DPP-IV enzyme activity in the studied patients

\begin{tabular}{|c|c|c|c|c|c|c|}
\hline \multirow[t]{2}{*}{ Variables } & \multirow[t]{2}{*}{ B } & \multirow[t]{2}{*}{ SE } & \multirow[t]{2}{*}{ Wald } & \multirow[t]{2}{*}{ Significance } & \multicolumn{2}{|c|}{$95 \% \mathrm{CI}$} \\
\hline & & & & & Lower & Upper \\
\hline Constant & 13.89 & 4.61 & 9.06 & 0.003 & & \\
\hline Recurrent attacks of abdominal pain & 0.004 & 0.001 & 8.84 & $0.00^{* *}$ & 0.994 & 0.999 \\
\hline Food selectivity & 0.00 & 0.001 & 0.045 & 0.832 & 0.83 & 0.99 \\
\hline
\end{tabular}

Dependent variable: Serum DPP-IV enzyme activity. *Highly significant difference at p<0.01. DPP-IV: Dipeptidyl peptidase-IV, CI: Confidence interval, SE: Standard error

Table 7: Multiple logistic regression analysis of factors associated with high serum casein antibody level in the studied patients

\begin{tabular}{llllll}
\hline Variables & B & SE & Significance & & 95\% CI \\
\cline { 4 - 6 } & & & & Lower & Upper \\
\hline Constant & 13.89 & 4.61 & 0.003 & 0.981 & 0.991 \\
Recurrent attacks of abdominal pain & 0.014 & 0.003 & $0.00^{* *}$ & 0.00 & 0.98 \\
Food selectivity & 0.008 & 0.002 & $0.00^{* *}$ & &
\end{tabular}

Dependent variable: serum casein antibody level. ${ }^{* *}$ Highly significant difference at $\mathrm{p}<0.01$. CI: Confidence interval, SE: Standard error

formation of small undigested harmful casomorphine (opioid) peptides that in turn leak into the bloodstream and cross the blood-brain barrier, reacting with brain areas such as the temporal lobes which are responsible for speech and auditory integration. Furthermore, Onore et al. [11] and de Magistris et al. [29] found high levels of antigenspecific antibodies for casein in autistic children.

In our present study, the mean serum DPP-IV activity was recorded to be lower in children with autism compared to asymptomatic controls. This result is in parallel to that obtained previously by Bashira and AL-Ayadhi [12] who stated that serum DPP-IV activity is found to be lower in children with autism compared to controls. They suggested that alterations in the serum activity of DPP-IV play a role in the pathophysiology of autism, and some have an allergic response to casein associated with a very significant downregulation in CD26 expression in lymphocytes.

In our present study, multiple logistic regression analysis revealed significant association between the high serum levels of antibodies to casein, food selectivity and recurrent attacks of abdominal pain $(\mathrm{p}<0.05)$, while the low serum DPP-IV enzyme activity was associated with recurrent attacks of abdominal pain in the studied patients with a prediction of $95 \%(p<0.05)$. There were no sex differences in the serum level of casein antibodies and DPP-IV activity.

Although diet free from casein was recommended for patients with autism, the potential of this diet is still under discussion. Bashira and
AL-Ayadhi [12] suggested a new modality for the elimination of the opioid effect in autistic children using DPP-IV enzyme therapy before, during, or after meals, but no trials of supplementation of DDP-IV enzymes as digestive enzymes were done in children with autism.

\section{CONCLUSION}

In children with ASD, recurrent attacks of abdominal pain were associated with high serum levels of casein antibodies and deficient in serum DPP-IV enzyme activity. This study provides the opportunity for new line treatment of GI symptoms in autistic children through using a supplemental digestive enzyme formula. More studies are warranted before this digestive enzyme can be widely recommended.

\section{AUTHORS CONTRIBUTION}

Inas R. EL-Alameey: responsible for concept, collection of samples, analysis and interpretation of data; drafting and revising of the manuscript. Hanaa H. Ahmed: Responsible for biochemical analysis, and revising of the manuscript. Ihab M Eid: Revising of the manuscript. Ghada El-Dory: revising of the manuscript. Manal Gameel: Collection of samples, revising of the manuscript.

\section{CONFLICTS OF INTERESTS}

The authors declare that they have no conflict of interest. 


\section{REFERENCES}

1. American Psychiatric Association. Diagnostic and Statistical Manual for Mental Disorders. $5^{\text {th }}$ ed. Washington, DC, USA: American Psychiatric Association; 2013.

2. Lai MC, Lombardo MV, Baron-Cohen S. Autism. Lancet 2014;383:896-910

3. Jyonouchi H, Geng L, Ruby A, Reddy C, Zimmerman-Bier B. Evaluation of an association between gastrointestinal symptoms and cytokine production against common dietary proteins in children with autism spectrum disorders. J Pediatr 2005;146:605-10.

4. Høst A, Halken S, Jacobsen HP, Christensen AE, Herskind AM, Plesner K, et al. Clinical course of cow's milk protein allergy/ intolerance and atopic diseases in childhood. Pediatr Allergy Immunol 2002;13 Suppl 15:23-8.

5. Rancé F. Food allergy in children suffering from atopic eczema. Pediatr Allergy Immunol 2008;19:279-84.

6. Tromp IL, Jong JC, Lebon A, Renders CM, Jaddoe VW, Hofman A, et al. The introduction of allergenic foods and the development of reported wheezing and eczema in childhood: The generation study. Arch Pediatr Adolesc Med 2011;165:933-8

7. Schade RP, Van Ieperen-Van Dijk AG, Versluis C, Van Reijsen FC, Kimpen JL, Bruijnzeel-Koomen CA, et al. Cell-surface expression of CD25, CD26, and CD30 by allergen-specific T cells is intrinsically different in cow's milk allergy. J Allergy Clin Immunol 2002;109:357-62.

8. Hunter LC, O'Hare A, Herron WJ, Fisher LA, Jones GE. Opioid peptides and dipeptidyl peptidase in autism. Dev Med Child Neurol 2003;45:121-8.

9. Shattock P, Hooper M, Waring R. Opioid peptides and dipeptidyl peptidase in autism. Dev Med Child Neurol 2004;46:357.

10. de Theije CG, Wu J, da Silva SL, Kamphuis PJ, Garssen J, Korte SM, et al. Pathways underlying the gut-to-brain connection in autism spectrum disorders as future targets for disease management. Eur $\mathrm{J}$ Pharmacol 2011;668 Suppl 1:S70-80.

11. Onore C, Careaga M, Ashwood P. The role of immune dysfunction in the pathophysiology of autism. Brain Behav Immun 2012;26:383-92.

12. Bashir S, AL-Ayadhi L. Alterations in plasma dipeptidyl peptidase IV in autism: A pilot study. Neurol Psychiatry Brain Res 2014;20:41-4.

13. American Psychiatric Publishing. Autism Spectrum Disorder Fact Sheet. Arlington, Va, USA: American Psychiatric Publishing; 2013.

14. Schopler E, Reichler RJ, Renner BR. The Childhood Autism Rating Scale (CARS): For Diagnostic Screening and Classification of Autism. Los Angeles, Calif, USA: Western Psychological Services; 1994.

15. Cermak SA, Curtin C, Bandini LG. Food selectivity and sensory sensitivity in children with autism spectrum disorders. J Am Diet Assoc 2010;110:238-46

16. Greenberg R. Human casein. Amino acid sequence and identification of phosophrylation sites. J Biol Chem 1984;259:5132-8.

17. Eigsti IM, Shapiro T. A systems neurosciences approach to autism: Biological, cognitive, and clinical perspectives. Ment Retard Dev Disabil Res Rev 2003;9:205-15.

18. Bhagat V, Jayaraj J, Haque M. Parent's self-efficacy, emotionality, and intellectual ability impacting the intervention of autism spectrum disorders: A review proposed model for appraisal of intervention. Int J Pharm Pharm Sci 2015;7:7-12.

19. Arndt TL, Stodgel CJ, Rodier PM. The tetralogy of autism. Int J Dev Neurosci 2005;23:189-99.

20. Itzchak EB, Zachor DA, Harofeh A. Male: Female Ratio is Related to Autism Spectrum Disorder in the Family and to Maternal Age. Zerifin, Israe: Harofeh Medical Center, Franklin Hall B Level 4 (Philadelphia Marriott Downtown); 2010.

21. Noens I, van Berckelaer-Onnes I, Verpoorten R, van Duijn G. The com for: An instrument for the indication of augmentative communication in people with autism and intellectual disability. J Intellect Disabil Res 2006;50:621-32

22. Volkmar FR, Klin A. Issues in the classification of autism and related conditions. In: Paul R, Cohen D, editors. Handbook of Autism and Pervasive Developmental, Neurobiology, and Behavior. Hoboken, NJ: Wiley; 2005. p. 5-41

23. Xi CY, Ma HW, Hua TY, Zhao YJ. Behavioral patterns of autistic children during infancy. Zhongguo Dang Dai Er Ke Za Zhi 2006;8:470-2.

24. Filipek PA, Accordo PJ, Baranek GT. The screening and diagnosis of autistic spectrum disorders. J Autism Dev Disord 1999;29:439-84.

25. McPartland PJ, Klin A. Asperger's syndrome. Adolesc Med Clin 2006; 17:771-88

26. Juneja M, Mukherjee SB, Sharma S. A descriptive hospital based study of children with autism. Indian Pediatr 2005;42:453-8.

27. Valicenti-McDermott M, McVicar K, Rapin I, Wershil BK, Cohen H, Shinnar S, et al. Frequency of gastrointestinal symptoms in children with autistic spectrum disorders and association with family history of autoimmune disease. J Dev Behav Pediatr 2006;27:S128-36.

28. Campbell DB, Buie TM, Winter H, Bauman M, Sutcliffe JS, Perrin JM, et al. Distinct genetic risk based on association of MET in families with co-occurring autism and gastrointestinal conditions. Pediatrics 2009; $123: 1018-24$

29. de Magistris L, Picardi A, Siniscalco D, Riccio MP, Sapone A, Cariello R, et al. Antibodies against food antigens in patients with autistic spectrum disorders. Biomed Res Int 2013;2013:729349. 